\title{
The Use of Vitamin $\mathrm{B}_{12 \mathrm{~b}}$ in Psychiatric Practice
}

\author{
H. L. Newbold, M.D.
}

\section{INTRODUCTION}

The recorded history of the use of vitamins in the treatment of mental illness goes back more than 2000 years, to a period long before lime juice was made required fare in the British Navy in $1795^{1}$. The British rediscovered the forgotten Roman fact that ascorbic acid containing fruits would prevent, as well as cure, scurvy.

Prior to this discovery, British sea captains, in their instruction manuals, were advised to provide recreation and music of a stimulating nature, as well as uplifting conversations, to treat the depressions which occurred with scurvy. Perhaps there are lessons to be learned from this ancient attempt at curing mental illnesses through environmental manipulations, when in reality a chemical defect existed.

Well known is the work of Goldberger during the 1930's which resulted in the virtual disappearance of the widespread psychosis associated with pellagra. Cleckley, Sydenstricker and Geeslin (1939) ${ }^{2}$ reported

This paper was presented at the joint meeting of The American Schizophrenia Association, The Canadian Schizophrenia Association and The Schizophrenia Association of Great Britain; London, England, September 28-30, 1971.

From, Department of Psychiatry, Lenox Hill Hospital, New York.

Reprints may be obtained from: H. L. Newbold, M.D., 251 East 51st Street, New York, New York 10022 alleviation of severe psychiatric symptoms with the use of moderately large doses of Nicotinic Acid ( 0.3 to 1.5 grams per day). None of these patients had the physical stigma associated with pellagra.

In 1952 Hoffer and Osmond began using massive doses of Nicotinic Acid (3 to 30 gm. per day) and ascorbic acid (3 to 9 gm. per day) for the treatment of schizophrenia. Since then they have published their findings ${ }^{3,4,5}$ and have done much to popularize what they termed megavitamin therapy, now expanded into Orthomolecular therapy by Linus Pauling (1968) ${ }^{6}$.

The latest impetus for the use of vitamins in the treatment of mental disorders comes from a paper published by Linus Pauling (1968) ${ }^{6}$ in which he points out the wide variations of vitamin requirements for individual organisms.

Since most chemical reactions in living organisms require catalyzation by enzymes, vitamin levels are of critical importance. If there is a genetically defective enzyme system, the vitamin level for ideal function may be much higher than the accepted norm. Some defective enzyme systems can apparently be forced to function at a normal level with an increase in the vitamin required for that particular chemical reaction.

ORTHOMOLECULAR PSYCHIATRY 27 
The Michaelis-Menten ${ }^{7}$ equation illustrates this principle:

$$
\mathrm{R}=\frac{\mathrm{d}[\mathrm{S}]}{\mathrm{dt}}=\frac{\mathrm{kE}[\mathrm{S}]}{[\mathrm{S}] \div(\mathrm{l} / \mathrm{K})}
$$

Only several parts or this equation are or particular interest to illustrate my point.

[S] is the concentration of the substrate. $\mathrm{E}$ is the total concentration of the enzyme. $K$ is the equilibrium constant for the production of the enzyme complex ES. $\mathrm{k}$ is the reaction rate constant for the breakdown of the complex into the enzyme and the reaction products.

If $\mathrm{K}=2$ is the normal constant for the formation of an enzyme complex, then only normal amounts of, say, vitamins will be required for the chemical reaction to proceed in the normal fashion.

If there be a genetic defect, however, and $\mathrm{K}=$ 0.01 , then it will be necessary to increase the vital substance, say a vitamin, by a factor of 200x for the rate of the chemical reaction to proceed at a normal rate. Thus, a very large increase in the vitamin level of the organism can "force" the chemical reaction.

\section{Causes of Vitamin $B_{12}$ Deficiency}

It is well known that a deficiency of vitamin $B_{12}$ can cause demonstrable lesions both in the spinal cord and in the brain proper. A vitamin $\mathrm{B}_{12}$ deficiency with change in the central nervous system may precede the actual appearance of anemia by several years.

Vitamin $\mathrm{B}_{12}$ deficiency may be produced by a low intake of the extrinsic factor, when patients follow a vegetarian diet, for example. Autoimmune reactions may block or bind the intrinsic factor so that vitamin $\mathrm{B}_{12}$ cannot be absorbed $^{8}$. Also autoimmune reactions may be directed against the parei-tal cell, destroying its ability to produce the intrinsic factor ${ }^{9}$.

A defect in the protein molecule which transports the vitamin $\mathrm{B}_{12}$ from the blood into the tissue may result in an effective tissue deficiency of vitamin $B_{12}$ even when the serum $B_{12}$ level is normal $^{10}$.

Of course, it has long been known that a vitamin $\mathrm{B}_{12}$ deficiency may result from infestation by the fish tapeworm diphyllobo-thrium or from excessive bacteria in the gut, such as may occur in the blind loop syndrome.

Various drugs may bring about a deficiency of vitamin $\mathrm{B}_{12}$; Dilantin is probably the most important offender.

\section{Serum $\mathbf{B}_{12}$ Studies}

A number of studies have been done in which the $B_{12}$ serum concentrations of psychiatric patients have been performed. No attempt will be made here to review all these papers, but in general the percentages have run from $0.02 \%$ to a high of $16 \%$ (including borderline values). Of interest are the recent findings of Edwin (1965) ${ }^{11}$, Hansen $(1969)^{12}$, Hutner $(1967)^{13}$, Shulman $(1967)^{14}$, Buxton (1969) ${ }^{15}$, Murphy $(1969)^{16}$, Carney $(1969)^{17}$ and Philpott (1971) ${ }^{18}$.

It has been estimated by Edwin $^{8}$ that approximately $0.5 \%$ of the general population in his area of Norway suffer from pernicious anemia.

This author is about to present the serum $B_{12}$ levels on a total of 221 psychiatric patients.

\section{Population Selection}

Each of the 221 patients with low serum $B_{12}$ reported here consulted me for a psychiatric problem. It should be pointed out that only one of the patients represented here is less than 16 years old. Previous to developing an interest in serum $\mathrm{B}_{12}$ levels, I saw a high percentage of young psychiatric patients. However, immediately preceding the present study, I began limiting my practice to the adult psychiatric population.

There is a further selection in patients presented here in that the author deals 
primarily with patients suffering from severe emotional illnesses. This means that the most frequent diagnosis represented is the syndrome of schizophrenia. As a rule, the author sees only patients who have failed to improve with previous psychiatric help. Most of the patients consulted three or four other psychiatrists before seeing me. It is apparent from these remarks that the patients represented here are not a cross-section of the categories usually treated by the general practice psychiatrist.

Of further interest is the fact that 93 of these patients are from the New York/Boston area and 128 of the patients come from North Carolina and the states adjacent to it. An interesting contrast in the serum $B_{12}$ levels was discovered in these two geographic representations in the present study.

\section{Results of Serum $B_{12}$ Studies}

The reader is referred to Table I.

Of the total of 93 patients seen from the New York/Boston area, $16.1 \%$ had what is generally considered a borderline low serum $\mathrm{B}_{12}$ level (150 picograms per milli-litre to 200 picograms per millilitre). $17.2 \%$ of these patients had a serum $\mathrm{B}_{12}$ level of less than 150 picograms per millilitre. When we total low $\mathrm{B}_{12}$ level patients, including all with serum $B_{12}$ levels less than the normal 200 picograms per millilitre, we find that $33.3 \%$ of this New York/Boston population had abnormally low serum $\mathrm{B}_{12}$ levels.

Of the patients from the general area of North Carolina, $6.3 \%$ had serum $\mathrm{B}_{12}$ levels of between 150 and 200 picograms per millilitre, $9.4 \%$ of the patients had serum $B_{12}$ values of less than 150 picograms per millilitre, giving an overall total figure of $15.7 \%$ of these patients with serum $B_{12}$ levels below the norm of 200 picograms per millilitre.

When the two different populations are averaged together, we find that $10.9 \%$ of the patients had a serum $B_{12}$ level between 150
Table 1

\begin{tabular}{llr}
\hline New York Total 93 & & \\
$150-200 \mathrm{pcg} / \mathrm{ml}$ & $=15$ & $16.1 \%$ \\
less than $150 \mathrm{pcg} / \mathrm{ml}$. & $=16$ & $17.2 \%$ \\
Total Low & & $33.3 \%$ \\
N.C. Total 128 & $=8$ & $6.3 \%$ \\
$150-200 \mathrm{peg} / \mathrm{ml}$ & $=12$ & $9.4 \%$ \\
less than $150 \mathrm{peg} / \mathrm{ml}$ & $=20$ & $15.7 \%$ \\
Total Low & & \\
Total 221 & $=23$ & $10.9 \%$ \\
$150-200 \mathrm{peg} / \mathrm{ml}$ & $=28$ & $12.7 \%$ \\
less than $150 \mathrm{peg} / \mathrm{ml}$ & $=51$ & $23.6 \%$ \\
Total Low & & \\
\hline
\end{tabular}

and $200 \mathrm{peg} / \mathrm{ml}$ and $12.7 \%$ of the patients had a serum $\mathrm{B}_{12}$ level less than $150 \mathrm{peg} / \mathrm{ml}$, giving a total for the entire group of $23.6 \%$ of patients with serum $\mathrm{B}_{12}$ levels less than $200 \mathrm{peg} / \mathrm{ml}$.

\section{Comments on Contrasting Geographic Serum $B_{12}$ Levels}

One can only speculate on the causes for the difference in the serum $B_{12}$ levels of the patients from the New York/Boston area and those from North Carolina and the adjacent states. The figures from the North Carolina area come from at least three different laboratories but the great majority of the tests were performed at the Washington Reference Laboratory in Washington, D.C.

Most of the serum $B_{12}$ levels from the New York area were performed at the Reference Laboratory, North Hollywood, California. A scattering of the tests from the New York area was performed at a number of different laboratories.

One might speculate what differences in diet in the two geographic areas might cause a difference in the serum $\mathrm{B}_{12}$ levels; however, this seems unlikely. Apparently, diet has very little effect on the serum $B_{12}$ level unless a vegetarian diet is being followed. A few of the author's patients in the 
North Carolina area were from the Seventh Day Adventist religion and did not eat meat. None of these patients happened to have low serum $B_{12}$ levels, however.

There were a few alcoholics in each geographical group, but if anything, the alcoholics seen in the New York area were better nourished and less desperately ill than those of the North Carolina area. Certainly there are genetic differences in the groups of patients seen in the two geographic areas. The N.C. area was heavily weighted with patients of English, Scottish-Irish and German ancestry, whereas in the New York area there was a high percentage of persons of Jewish and pure Irish ancestry. As a group, it is the author's opinion that the people of New York are generally sicker than those from the N.C. area and had been ill for a longer period of time. In the author's opinion, the group from New York in general represented a more aggressive population and one with an overall higher intelligence.

Although these patients were not tested for fish tapeworm, there is no reason to think that fish tapeworm would be any more common in the New York area than in the N.C. area and blind loops of intestine should not be more common in the New York group.

Since the absorption of vitamin $\mathrm{B}_{12}$ from the gut is largely dependent upon certain intact enzyme systems, which are inherited, one might speculate that the New York group is genetically different from the N.C. group.

\section{Clinical Experience with $\mathbf{B}_{12}$}

If one scans the literature concerning vitamin $\mathrm{B}_{12}$, it is relatively easy to pick up studies in which psychiatric populations have been tested for serum $\mathrm{B}_{12}$ levels; however, less information is available giving the results of therapy with vitamin $\mathrm{B}_{12}$. In general, reports by Smith $(\mathrm{I960})^{19}$, Stra-chan $(1965)^{20}$ and Shulman $(1967)^{21}$, were enthusiastic about the use of vitamin $\mathrm{B}_{12}$ in senile and confusional states; however, Hughes $(1970)^{22}$ gives a negative report. I would like to present some clinical cases illustrating my experience with vitamin $B_{12}$, with the hope that more physicians will become alert to the possibilities of the therapy of mental illness of certain patients with the use of injected vitamin $B_{12}$.

\section{Case 1.}

The first patient illustrating the use of vitamin $B_{12}$ shows a most dramatic improvement with the medication.

He is a 33-year old white male who is a Ph.D. candidate at one of the country's major universities. Because he was not making progress in therapy, the patient was referred to me by his analyst for a chemical work-up.

Two years prior to seeing me, the patient had experienced a psychotic break. At that time he sat in his room and talked to himself for several days. He was completely out of touch with reality. For about two weeks he had experienced what he described as a snapping sensation in his head. He explained that space had been greatly foreshortened, that he felt like a midget. The streets seemed extremely short.

At the start of his psychosis he was so frightened that he left his apartment and began running up and down the street. He was convinced that a blood vessel had broken in his head. His attention span was quite short.

After three or four days of totally psychotic behavior, he was admitted to one of New York's most respected hospitals, where he was placed on Chlorpromazine (Thorazine). After a few days the more florid aspects of his psychosis were under control. After discharge from the hospital, he was maintained on Chlorpromazine, which was gradually reduced. He was taking only 50 mgs. at bedtime when he consulted me. 
During the two years following his hospitalization, the patient had felt very lethargic. Work on his Ph.D. thesis had been impossible. He felt lonely and insecure and it was very difficult for him to interact with other people.

The patient's wife left him after his psychotic break. This only added to his feelings of inadequacy and insecurity. His head still felt as if it were not clear. His emotions seemed locked within him. He secretly harbored anger toward most people. It was difficult for him to drag himself to class. In class, he was unable to participate in an active way. His memory was very poor and he felt depressed. It was quite difficult for him to comprehend and remember what he read.

At the time he consulted me, the patient's affect was flat and he spoke in monotones. He was oriented in significant spheres. No definite perceptual defects were present. He had vague paranoid feelings. A clinical examination of his memory and recall were normal.

A chemical work-up revealed an ATP level of $5.10 \mathrm{mgs} / \%$, an NAD level of $1.04 \mathrm{mgs} / \%$. A salt dumping test was negative, as was a six-hour glucose tolerance test. A routine blood count and urine was normal. BUN was 18.7, PBI $8.0 \mathrm{mgs} / \%$, T3 was 24\%, T4 was 4.8\%. Serum $\mathrm{B}_{12}$ level was 103 pico-grams per millilitre. An HOD test was negative. A hair test for minerals revealed a lead level of 4.1 mgs/\%, a normal iron level of $4.6 \mathrm{mgs} / \%$, a normal manganese level of $0.26 \mathrm{mgs} / \%$, a normal calcium level of $40 \mathrm{mgs} / \%$, a normal magnesium level of $6.67 \mathrm{mgs} / \%$, a slightly depressed potassium level of $3.5 \mathrm{mgs} / \%$, a normal copper level of $2.6 \mathrm{mgs} / \%$, a slightly depressed sodium level of $9.5 \mathrm{mgs} / \%$ and a somewhat elevated zinc level of $18.8 \mathrm{mgs} / \%$.

The patient was requested to take a computerized Minnesota Multiphasic Personality Inventory but he was unable to concentrate on the test and refused to take

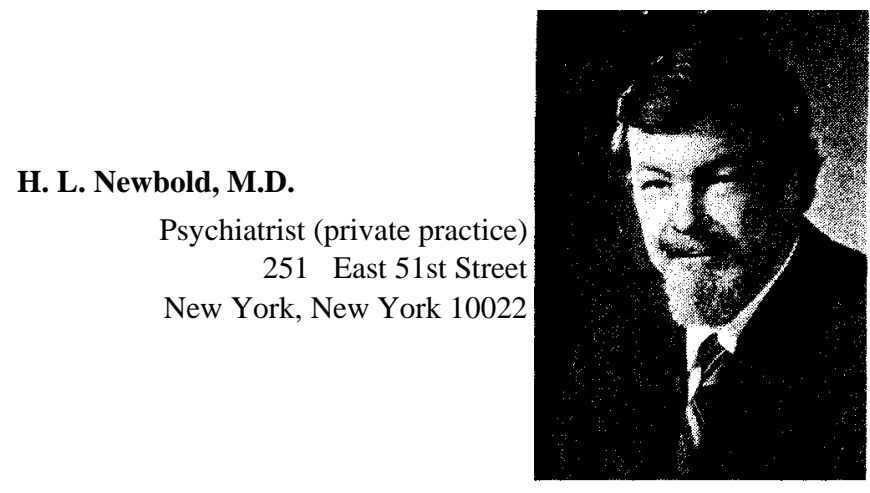

it because the attempt at concentration made him angry and upset.

Following his laboratory tests, the patient was given $\mathrm{B}_{12}$ b (Hydroxocobalamin) 1000 mgs. intramuscularly on June 4, 1971. When he returned to the office on June 9, 1971, he reported no change in his condition. A second intramuscular injection of hydroxocobalamin 1000 mgs. was administered at that time. When the patient reported to the office again on June 17, 1971, he spoke of a remarkable improvement of his condition. At that time his memory was much improved and he found that he was learning well. He was participating in class activities and for the first time in two years, was hard at work writing his Ph.D. thesis. He still felt angry occasionally with people but this did not bother him as before. The sense of depression had lifted. Clinically, the patient had developed a normal affect and he was able to relate well with me.

During the five months I have been seeing this patient, he has, with two exceptions, maintained an excellent level of improvement. The nurse at the office of his local medical doctor administered hydroxocobalamin 1000 mcg. intramuscularly twice weekly.

When this interval between injections was gradually increased to once weekly, the patient maintained his feeling of well-being. However, on the two occasions when we have tried to increase the injection 


\section{ORTHOMOLECULAR PSYCHIATRY}

interval to ten days, the patient quickly became tired, depressed and had difficulty concentrating. Each time the symptoms rifted promptly upon decreasing the interval between injections to seven days. It would have been most interesting to have observed the effect of vitamin $B_{12}$ on this patient at the time of his original psychotic break.

\section{Case 2.}

The second patient chosen to illustrate a point in the therapy with vitamin $B_{12}$ is a 38-year old white woman with a many-year history of recurrent periods of severe depression and of disabling physical complaints, for which a clear anatomical diagnosis could not be made. She had been helped temporarily by psychotherapy. Of particular significance was the fact that her serum $\mathrm{B}_{12}$ level was 231 picograms per millilitre.

In spite of this normal serum $B_{12}$ level, I decided to give the patient a trial on hydroxocobalamin. The decision was based on Linus Pauling's article (1968), in which he pointed out that some genetically defective enzyme systems might function more effectively on vitamin levels much higher than the accepted norms.

At the time the hydroxocobalamin injections were started the patient was being carried on diazepam (Valium) 5 mgs. four times daily and chlorprothixene (Tar-actan) 10 mgs. five times daily. This combination of medications had been arrived at through trial and error. The medication enabled her to avoid some of her acute distress but she was not able to function even close to adequately in her role as a housewife.

Approximately a year ago, she was administered her first injection of hydroxocobalamin $1000 \mathrm{mcg}$. She experienced an immediate increase in her energy and feeling of wellbeing. She reported, however, at the time of her visit a week later, that the improvement lasted only about two and a half days. Interestingly enough, this is about the length of time one can expect high tissue levels of $\mathrm{B}_{12}$ after an injection of hydroxocobalamin.

Instructions were given to her family physician to repeat the hydroxocobalamin injection every two and a half days. At the time of the patient's next visit to me, she was markedly improved. She was less depressed. Her energy level was greatly improved, and she was rapidly losing her physical complaints.

Approximately two weeks later the patient was still improving in all spheres. On her own, she soon began experimenting by letting herself go three or four days on occasion between injections of hydroxocobalamin. Each time, she noticed a definite reduction in her energy level and her feeling of wellbeing.

This patient was maintained on hydroxocobalamin injections $100 \mathrm{mcg}$. every two and a half days for approximately ten weeks, at the end of which time her interval between injections was gradually increased, so that now her injections come only about every two weeks. She has continued her improvement. In addition to the large family which she cares for, she has been employed full time in a very stressful position.

This patient was tried on many combinations of medication, including various injections, prior to her receiving hydroxocobalamin. No previous treatment had given her even temporarily satisfactory remissions. It is felt that this patient has an enzyme defect which requires larger than normal amounts of hydroxocobalamin.

\section{Case 3.}

This patient is a 28-year old white male who has spent most of the last ten years of his life in a State hospital. He had two courses of electroconvulsive treatment. After the first course, he was considerably improved but soon relapsed. He was some- 
what improved after the second course but quickly relapsed. Prior to my seeing the patient, he was on heavy doses of chlorpromazine (Therazine), niacin and ascorbic acid.

He was fed the usually inadequate state hospital diet. The patient was extremely negativistic, was completely out of touch with reality. He could not carry on a conversation, he had numerous delusions, a very short attention span and his behavior was characterized by frequent outbursts of anger, so that it was almost impossible for him to have even brief visits at home.

The patient was found to have a serum $B_{12}$ level of 155 picograms per millilitre and was started on injections of hydroxoco-balamin 1000 milligrams twice weekly. His other medication was continued. The patient showed no appreciable response for the first six to eight weeks after beginning the hydroxocobalamin. At that time, he began gradually becoming calmer and less negativistic. For example, it was no longer necessary to have him forcibly restrained for his injections of hydroxocobalamin. Soon, he was able to go out on passes with his family with less difficulty. For the first time in many years, he expressed an interest in his clothes. His weight increased and he began to lose the wild, disheveled look of madness which had been so characteristic of him previously. His attention span increased so that he was able to work for long periods in occupational therapy and complete complex drawings. His grasp of reality remained spotty.

In my judgment, there has been a modest improvement in his condition, though he still remains schizophrenic.

Since this patient was also receiving niacin and ascorbic acid, it is possible he was one of those patients slow to respond to this therapy and that his improvement simply happened to correspond to the time when hydroxocobalamin was begun.

This patient may have had a marked vitamin $\mathrm{B}_{12}$ deficiency in spite of his modestly low serum $\mathrm{B}_{12}$ level of $155 \mathrm{pcg} / \mathrm{ml}$. If he happens to be one of those patients, like case 2, who requires high levels of $\mathrm{B}_{12}$ for his optimum function, then the level of $155 \mathrm{pcg} / \mathrm{ml}$ may be extremely low for this particular individual.

\section{Case 4.}

The next patient was the only juvenile included in the present series. This 6-year old white child came from a family with a strong history of schizophrenia. At the time I saw him, he was quite hyperactive and immature for his age. He was pale and thin and had a very short attention span. The patient was shy and withdrawn.

A serum $B_{12}$ level revealed $140 \mathrm{mcg} / \mathrm{ml}$. At the time hydroxocobalamin was started, the patient was taking ascorbic acid 500 mgs. three times daily, niacinamide 500 mgs. three times daily, a multivitamin capsule once daily and calcium gluconate 1 gram daily as well as methylphenidate HC1 (Ritalin) 5 mgs. twice daily. He was given diphenhydramine HC1 (Benadryl) 25 mgs. at bedtime for sleep. The patient had improved somewhat on this regime, which had been followed for a number of months. He was unable to tolerate larger doses of methylphenidate HC1 (Ritalin).

It can easily be understood that both the patient's mother and I were reluctant to give a child of 6 years old intramuscular injections. However, his level of improvement was not adequate and in view of the low serum $B_{12}$ level, it seemed mandatory that he receive the vitamin. He was accordingly given hydroxocobalamin $1000 \mathrm{mcg}$. intramuscularly one time a week. He reacted violently to having the injection, so that it was necessary to hold him and forcibly administer the medication. Since this seemed likely to interfere with the rapport between us, the patient was sent to his pediatrician for future injections.

The next week, when the patient 
returned, the mother reported that he had been a great deal calmer for approximately three days following the injection. In that period, he was more tractable, he slept better, he was less hyperactive, less clinging to her, more outgoing and generally much more pleasant to live with. It is interesting to note that the mother reported that the pale, sickly color of his skin improved a great deal for several days after the injection.

Because the mother gave a history of the patient having relapsed approximately three days following his injection, it was decided to start him on hydroxocobalamin $1000 \mathrm{mcg} / \mathrm{ml}$ intramuscularly twice weekly. With this increase in frequency of administration, the patient maintained his new level of improvement throughout the week. For a little more than a year, the patient has continued receiving his injections of hydroxocobalamin.

On several occasions, I have attempted to space the injections over a longer period of time; however, the former symptoms always return when the interval between injections is increased. I might add that this mother is generally reluctant to have the child on medication and has attempted, several times, with this and other medications, to gradually discontinue them on her own. However, she has always returned to the schedule of injections twice weekly because of the return of symptoms.

Later, this patient was taken off Ritalin and placed on daenol acetamidobenzoate (Deaner) 300 mgs. in the morning. He showed a rather definite improvement with the substitution of Deaner for Ritalin. Since being given the Deaner, again attempts have been made to reduce the frequency of hydroxocobalamin. However, the symptoms always become worse when the hydroxocobalamin interval is increased. It is therefore continued and will be continued apparently indefinitely at this level.

The patient is now progressing quite well. He is attending school and for the first time able to keep up with his peer group.

\section{Other Patients}

It is understandably difficult to evaluate the role of hydroxocobalamin in treating patients with mental illnesses. The author has had other patients who, he suspects, have improved with the addition of hydroxocobalamin to their psychochemother-apeutic regime; however, other modalities were used in treating the patients and the percentage of improvement attributable to vitamin $B_{12}$ injections was difficult to assess. Some patients with low serum $B_{12}$ levels did not significantly improve with the addition of injections of hydroxocobalamin to their therapeutic regime.

Certainly it is theoretically possible that brain damage can proceed to the point of being irreversible in vitamin $B_{12}$ deficiency. The administration of vitamin $\mathrm{B}_{12}$ in certain patients would simply prevent further insults to the central nervous system.

It is believed that vitamin $B_{12}$ is needed in at least ten different enzyme systems throughout the body. It is important in the formation of RNA.

Of interest is the fact that $\mathrm{B}_{12}$, along with folic acid, is needed in the biosynthesis of methyl groups ${ }^{23}$.

The author had one adverse reaction to the administration of hydroxocobalamin $1000 \mathrm{mcg}$. intramuscularly. This patient was a highly abnormal 18-year old boy who was mentally defective. He was a behavior problem. It was very difficult to maintain him outside of the hospital, even with the use of tranquillizers. His serum $\mathrm{B}_{12}$ level was normal but I decided to give him a trial with an injection of hydroxocobalamin. About forty minutes after the injection, the patient became highly restless, irritable and negativistic. This disturbed state lasted for approximately two days.

The author is not aware of any other 
instances of any such reactions to vitamin $B_{12}$ injections. It is of interest to note, however, that some patients when placed on massive doses of niacin become hyperactive and irritable and it is necessary to place them on some tranquillizer such as Valium for a few weeks to control the over-stimulated central nervous system.

\section{CONCLUSIONS}

1. This first conclusion is not, properly speaking, a conclusion which arises from the information presented in this paper. However, the information is placed here because, with the ever mounting volume of medical literature, many physicians have time only to read the conclusions at the end of a paper.

In England, Foulds and others $(1970)^{24}$ have started a movement to remove the conventional form of vitamin $\mathrm{B}_{12}$ (cyanocobalamin) from the market. These authors feel that the cyanide radical is toxic for some patients and has produced optic nerve atrophy.

They propose that vitamin $\mathrm{B}_{12 \mathrm{~b}}$, (hydroxocobalamin) be substituted for cyanocobalamin. This seems wise for several other reasons. The body must transform cyanocobalamin into hydroxocobalamin before it is available for metabolic processes. Also hydroxocobalamin maintains high serum $B_{12}$ levels longer than does cyanocobalamin.

2. From a psychiatric office practice, a consecutive group of 221 patients has been tested for serum $\mathrm{B}_{12}$ levels. Of this group, $10.9 \%$ showed vitamin $\mathrm{B}_{12}$ serum levels of between 150 and 200 $\mathrm{pcg} / \mathrm{ml}$. The level between the 150 and $200 \mathrm{pcg} / \mathrm{ml}$ is considered by some authorities to be border line and by others to be low.

3. From the group of 221 patients tested, $12.7 \%$ had serum $B_{12}$ levels less than 150 $\mathrm{pcg} / \mathrm{ml}$.

4. Of the psychiatric patients tested, $23.6 \%$ were found to have borderline or low serum $B_{12}$ levels.

5. An interesting contrast was found be tween the serum $B_{12}$ levels in the psychiatric patients of the New York area as opposed to those in the Western Northern Carolina area. Of 93 patients tested in the New York area, 16.1\% were found to have serum $B_{12}$ levels between 150 and $200 \mathrm{pcg} / \mathrm{ml}$, whereas in the North Carolina sample of 128 psychiatric patients, only $6.3 \%$ fell in this category. In the New York area, $17.2 \%$ of the patients had serum $\mathrm{B}_{12}$ levels less than $150 \mathrm{pcg} / \mathrm{ml}$, whereas the North Carolina group showed $9.4 \%$ in this group.

Of the total low $\mathrm{B}_{12}$ determinations, the New York group showed $33.3 \%$ and the North Carolina group showed $15.7 \%$.

6. Several case histories illustrating the value of hydroxocobalamin (vitamin $\mathrm{B}_{12} \mathrm{~b}$ ) for the use in the treatment of psychiatric patients were presented.

It is my impression that hydroxocobalamin is of definite benefit to a small but significant percentage of psychiatric patients. Quite clearly, at least two (of the 221 patients) had dramatic improvements in their psychiatric illnesses following the use of

$\mathrm{B}_{12 \mathrm{~b}}$.

7. I would suggest that all people and especially patients with psychiatric complaints, should be tested for serum $B_{12}$ levels. When the serum $B_{12}$ level below 200 picograms per cc. is discovered, the patients should be given at least monthly injections of hydroxocobalamin 1000 $\mathrm{pcg} / \mathrm{ml}$ during the remainder of their lives. Surely this is worthwhile in view of the possible consequences of demylinazation of the spinal cord and the brain proper in states where the serum $\mathrm{B}_{12}$ level is low.

8. I feel that every psychiatric patient should be given a clinical trial of injections of hydroxocobalamin, regardless of his 
serum B12 level. If the patient feels improved after the injections, the proper interval between injections should be determined by trial and error. This is in accordance with the author's clinical experience, and agrees with the theoretical postulations put forth by Linus Pauling (1968) $)^{6}$

N.B. Although cyanocobalamin $\left(B_{12}\right)$ may be given even intraveinously or intramuscularly, hydroxocobalamin $\left(B_{12} b\right)$ should only be injected intramuscularly.

\section{REFERENCES}

1. Encyclopaedia Britannica, 1958, Vol. 20, p. 232. WiLliams, R. J. and DeAson, G.: Proc. Nat. Acad. Sci. U.S., 57, 1638, 1967.

2. Cleckley, H. M., Sydenstricker, V. P. and Geeslin, L. E.: J. Amer. Med. Ass. 112, 2107, 1939.

3. Hoffer, A.: Niacin Therapy in Psychiatry, Charles C. Thomas Co., Springfield, 111. 1962.

4. Hoffer, A. and Osmond, H.: Lancet 1, 316, 1962.

5. Hoffer, A. and Osmond, H.: Acta Psychiat. Scand. 40, 171, 1964.

6. PAuling, Linus: Int. J. Neuropsychiat. 2, 234, 1966.

7. Michaelis, L. and Menten, M.: Biochem, z. 49, 333, 1913.

8. SAMTER, MAX (Ed.): Immunological Diseases: pg. 1230, Little Brown \& Co., Boston, 1971.

9. TURK, J. L.: Immunologin in Clinical Medicine: pg. 161, Appleton-Century-Crofts, New York, 1969.

10. Hakami, N., Neiman, P. E., Canellos, G. P. and LAzERSON, J.: Neonatal Megaloblastic Anemia Due to Inherited Transcobalmin II Deficiency in Two Siblings: Vol. 285, No. 21, pg. 1163, New England Journal of Med., 1971.

11. Edwin, E., Holten, K., Norum, K. R.,

Schrumpf, A. and Skaug, O. E.: Acta Med. Scand. 177, 689,
1965.

12. Hansen, T., RAfAelsen, O. J. and R0DBRo, P.: Lancet 2, 965, 1966.

13. Hunter, R., Jones, M., Jones, T. G. and Matthews, D. M.: Brit. J. Psychiat. 113, 1291, 1967.

14. SHulman, R.: Brit. J. Psychiat. 113, 241, 1967.

15. Buxton, P. K. Davison, W., Hyams, D. E. and Ervine, W. J.: Gerontologia Clinica 11, 22, 1969.

16. Murphy, F., SRivastava, P. C, Varadi, S., and Elwis, A.: Brit. Med. J. 3,559, 1969.

17. CARneY, M. W. P.: Behavioral Neuropsychiatry, Vol. 1, No. 7, p. 19, October 1969.

18. PhilpotT, W. H.: Personal communication, 1971.

19. Sмith, A. D. M.: Brit. Med. J. 2.1840, 1960.

20. Strachan, R. W. and Henderson, J. G.: Quart. J. Med. 34, 303, 1965.

21. Shulman, R.: Brit. J. Psychiat. 113, 252, 1967.

22. Hughes, D., Elwood, P. C, Shinton, N. K. and Wrighton, R. J.: Brit. Med. J. 2, 458, 1970.

23. Best, C H. and Taylor, N. B.: The Physiological Basis of Medical Practice: Williams \& Wilkins Co., Baltimore, 1966.

24. Foulds, W. S., Foleman, A. G., Phillips, C. I. and WiLson, J.: Lancet p. 35, Jan 3, 1970.

REFERENCES (A. Pauline Ridges) Continued from page 26

63. Hoffer, A.: The effect of nicotinic acid on the frequency and duration of re-hospitaliza-tion of schizophrenic patients: A controlled comparison study. Int. J. Neuropsychiat. 234, 1966.

64. Ban, T. A. and Lehmann, H. E.: Nicotinic acid in the treatment of schizophrenias. Canad. Psychiat. Ass. J. 15:499, 1970.
65. Kline, N. S., Barclay, G. L., Cole, J. O., Esser, A. H., LehmanN, H. and WitTEnBoRn, J. R.: Controlled evaluation of NAD in the treatment of chronic schizophrenic patients. Brit. J. Psychiat. 113:731, 1967.

66. Gould, J.: Treatment of delirum, psychosis and coma due to drugs. Lancet 1:570, 1953. 